\title{
El trabajo en los call centers: La corporeidad de la experiencia laboral
}

Recibido: 6 de febrero 2019

Revisado: 14 de mayo 2019 Aprobado: 30 de agosto 2019

\section{Nancy Piedra Guillén}

Costarricense. Doctora en Ciencias Sociales con énfasis en Sociología. Directora del Programa de Posgrado Centroamericano en Sociología de la Universidad de Costa Rica. Profesora-investigadora de la Escuela de Sociología de la Universidad de Costa Rica

y el Posgrado

Centroamericano en

Sociología de la Universidad de Costa Rica. Especialista en estudios de género, relativos a la feminidad y la masculinidad, construcción

de procesos identitarios, relaciones de poder y género en el mundo público y privado. Diseño y planificación de políticas públicas con perspectiva de género; condiciones de trabajo y empleo, salud ocupacional y corporeidad del trabajo. Especialista en metodología en las ciencias sociales.

Correo electrónico: npiedraguillen@yahoo.com

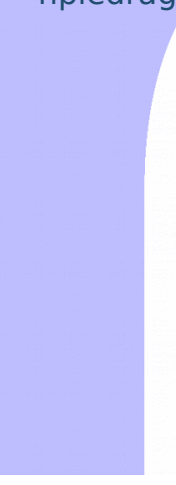

Resumen: En el presente artículo se ofrecen algunos de los resultados obtenidos en una investigación social que tenía por objeto explorar la vida cotidiana de trabajadores y trabajadoras de call centers (o centros de llamadas) en Costa Rica. Cumple como fin analizar las condiciones de trabajo, considerando la experiencia laboral de las personas entrevistadas y encuestadas desde su cuerpo y sus emociones, que se expresa como la corporeidad del trabajo. Se desea profundizar en la vivencia para intentar vincular aspectos que, por lo general, se dejan de lado cuando se estudia los procesos de transformación del trabajo. Es decir, se estudia las condiciones en que las personas trabajan y son empleadas y cómo estas experimentan desde la subjetividad, desde sus cuerpos y emociones las condiciones de empleo y trabajo. Puntualmente se contextualiza la temática, lo que permite ubicar el desarrollo de las empresas de subcontratación en el área de los servicios de telecomunicación. Posteriormente, se analiza las condiciones de empleo y trabajo, y entonces ahondar en el valor del trabajo, la temporalidad, la flexibilidad laboral y los efectos en la salud, así como la cultura de los call centers. Es un texto que nos permite adentrarnos en las vivencias de un grupo de trabajadores poco estudiado en el país.

Palabras clave: sociología del trabajo; sociología de las emociones; condiciones de trabajo; condiciones de empleo; corporeidad del trabajo

\section{Work in Call Centers: The Corporeality of work experience}

Abstract: This article presents some of the results obtained in a social investigation aimed at exploring the daily life of call center workers in Costa Rica. Its purpose is to analyze their working conditions and experience, through interviews and surveys from the perspective of their body and emotions: what I call the corporeity of work. The study dwells on:oj: intimate experience, and links elements which are usually left out when work transformation processes are studied. It observes the conditions in which people work and are employed and how they subjectively experience these conditions, from within their bodies and emotions. After briefly putting in context the subject matter and establishing the development of subcontracting companies in the area of telecommunication services, it analyzes the conditions of employment and work, and then delves into the value of work, temporality, labor flexibility and health effects, as well as call center culture. This text allows us to examine the life experience of a group of workers not often studied in the country.

Key words: sociology of work; sociology of emotions; working conditions; employment conditions; corporeity of work 
1. El nombre del Proyecto en la Vicerrectoría de Investigación es: Pry01-1128-2018-De la maquila textil a la maquila de los servicios: análisis comparativo de las condiciones de empleo, trabajo y vida cotidiana de las y los [sic] trabajadores de la industria textil y los call centers".

\section{El presente artículo} representa el primer esfuerzo que hace la investigadora para estudiar el mundo del trabajo extradoméstico considerando el cuerpo y las emociones desde otro ámbito de la vida: el del trabajo. El ámbito de estudio contrasta con lo que había sido su línea de indagación, en tanto estudiaba los afectos y las emociones desde la vida e intimidad de las parejas, considerando las relaciones de poder en estas.

3. Agradezco infinitamente a las personas que de forma desinteresada y solidaria compartieron sus relatos y a quienes contestaron el cuestionario. Sin su participación este trabajo no habría podido llevarse a cabo.

4. Vargas, Gabriel. 2015. Representaciones sociales en torno al trabajo: procesos de construcción identitaria, realización laboral y transitoriedad en las y los trabajadores de call center en Costa Rica. Tesis de Grado de Licenciatura, Escuela de Sociología, Universidad de Costa Rica. Verificar si este formato de referencia coincide con el de las páginas finales de este artículo..

\section{Introducción}

En el presente artículo se ofrecen algunos de los resultados obtenidos en una investigación social que cumplía por finalidad explorar la vida cotidiana de trabajadores del sector de la maquila textil y los call centers (o centros de llamadas) en Costa Rica ${ }^{1}$. El objetivo general del proyecto fue indagar sobre las condiciones de empleo y trabajo de los trabajadores de ambos sectores, la cotidianidad, la incidencia del trabajo en la salud, el valor del trabajo y el uso del tiempo. En el transcurso de la ejecución del proyecto, pensamos que sería adecuado analizar las vivencias de las personas considerando la corporeidad; e indagando desde el cuerpo y las emociones porque el trabajo se vive en el cuerpo y con el cuerpo, partiendo del caso de las personas que laboran en call centers.

Así que el objetivo del presente artículo es realizar un primer acercamiento analítico del material empírico que obtuvimos, centrado en las condiciones de trabajo y empleo desde la corporeidad de las emociones de las personas encuestadas y entrevistadas ${ }^{2}$. Nos referimos a la experiencia corporal y emocional que las condiciones de trabajo y empleo producen en las personas.

Puntualmente se contextualiza la temática, lo que permite ubicar el desarrollo de las empresas de subcontratación en el área de los servicios de telecomunicación y, posteriormente, se analiza las condiciones de empleo y trabajo, el valor del trabajo, la temporalidad, la flexibilidad y temporalidad, los efectos en la salud y la cultura de los call centers.

La muestra de la población no es representativa; fue seleccionada a partir de criterios claramente establecidos. Se contactó a personas que cumplieran con el perfil definido, que a su vez era bastante amplio: ser mayor de 18 años, mujeres y hombres que contaban con más de dos años de trabajar en call centers y captar distintas empresas. Las 16 personas contactadas contestaron un cuestionario; 12 de estas personas fueron entrevistadas ${ }^{3}$. Participaron más hombres que mujeres (doce y cuatro, respectivamente).

En tres casos, se entrevistó a individuos que hace cinco años habían sido entrevistados por el sociólogo, Gabriel Vargas, quien estudió la temática ${ }^{4}$ y a quien agradezco de forma especial por su gesto desinteresado y solidario al compartir su material. Fue muy interesante retomar el relato de estas personas; en los tres casos, continuaban trabajando en un call center.

Las entrevistas fueron transcritas en su totalidad y el material fue organizado, codificado y analizado por medio del programa Atlas-Ti. La riqueza que se desprende de sus narraciones nos permitirá, en el futuro, indagar en otros aspectos no tratados en este texto; pero, sin duda, en el artículo se abordan subtemas que fueron considerados como particularmente interesantes.

Las entrevistas se realizaron en lugares diferentes, definidos de acuerdo con las posibilidades y el tiempo de cada quien. Los nombres que aparecen en 
los testimonios utilizados son ficticios. Se trabajó también con fuentes secundarias como datos estadísticos, artículos de periódicos y se hizo una revisión exhaustiva de la literatura existente relacionada con el tema ${ }^{5}$.

\section{Presentación de la temática}

Varios son los cambios que se han vivido en el mundo del trabajo en los últimos 35 años; no cabe duda de que, en el caso costarricense, así como en general en Latinoamérica, las crisis económicas que ocurrieron en la década de los años 80 del siglo pasado impactaron el modelo de desarrollo económico.

El proceso de transformación socioeconómica, que aún no llega a su consolidación, muestra continuas crisis económicas estructurales en los países desarrollados y en los no desarrollados, enfatizando procesos de desigualdades socioeconómicas. Costa Rica, al ser un país que se había caracterizado desde mediados del siglo XX y hasta la década de los 70, como un lugar donde el bienestar de las personas era una meta importante, hoy dista de esa posibilidad; las brechas de desigualdad se ensanchan y no hay perspectiva de cambio en otra dirección. Era una sociedad donde, en alguna medida, ciudadanos se identificaban con la clase dominante, representación social que tiene su génesis desde el período de la Colonia.

Sin embargo, la idea o más bien el mito de la sociedad de los "igualiticos" ha empezado a desmoronarse, en el tanto se observan las asimetrías en distintos ámbitos -sociales, culturales y económicos (Sojo 2010). El proceso se ha agudizado y estamos ante un difícil y tenso momento histórico: la cuerda ya no da para más. En el Informe del Estado de la Nación se señala que si no hay cambio en las políticas públicas, pronto estaremos en un momento de no retorno, de fragmentación social y enfrentamientos de clase aún más agudos que los que hemos presenciado en los últimos años en el país:

"En síntesis, el país vive una época de mucho cuidado.

Enfrenta riesgos económicos, sociales, ambientales y po-

líticos, a los cuales se suman desafíos externos propicia-

dos por varios acontecimientos recientes. Los resultados

de esta transición dependerán de las respuestas del sis-

tema político, y necesariamente deben incluir cambios en

el estilo de desarrollo" (Estado de la Nación 2018). Es

claro que el momento es crítico y complejo.

Es necesario preguntarse y estudiar cómo se generan las desigualdades desde distintos ámbitos y cómo un campo interfiere en el otro y estos se retroalimentan. Por esa razón, estudiar lo que sucede en el mundo del trabajo
5. Si desea ahondar en la temática, le puede interesar el artículo en el que detallo sobre el estado de la investigación: Piedra Guillén, Nancy. Estado de la investigación en Centro América: Los talleres del mundo global, la maquila textil y los call centers (en prensa). En el artículo se presenta un balance crítico de las investigaciones que se han realizado en las últimas tres décadas sobre el tema de las transformaciones en el mundo del trabajo, el trabajo en el sector de la maquila textil y los call centers o centros de llamadas. 
nos permite comprender parte del proceso de cambio que se vive en las sociedades latinoamericanas en general y en la nuestra en particular. Tal proceso que se ha caracterizado por "la desregulación de las relaciones laborales y la consecuente disminución de la protección del trabajo, tuvo la finalidad de aminorar los costos empresariales, incrementar las ganancias para las empresas e incentivar la inversión y la captación de inversiones extranjeras" (Castillo, Baca y Todaro 2016, 7).

Así, el retorno de los estudios sobre el mercado, las desigualdades y el trabajo es un factor clave que nos permite comprender los procesos individuales y estructurales, pues facilita estudiar la corporeidad del trabajo, la vivencia y cómo las personas sobrellevan los procesos de cambio estructurales desde el cuerpo y las emociones, qué se genera para adecuarnos 0 , posiblemente, para sobrevivir de la mejor manera a las transformaciones, a las incertidumbres y a las desavenencias.

No es casual que existan muchas investigaciones que se han producido en las últimas tres décadas en Latinoamérica en las que ha habido distintas líneas lógicas de investigación (de la Garza 2007, 2015, 2017; y Zapata 2010).

Como desarrollamos con más detalle en otro artículo (Piedra 2019), hay grupos de estudio que enfatizaron en la crisis económica de los años 80 y su incidencia en el mundo del trabajo; destacan las investigaciones desde el enfoque de la regulación, con base en los trabajos de Aglietta, Boyer, Coriat y Lipietz, entre otros; dicha perspectiva pretendió sustituir la teoría de la dependencia. También se reconoce el surgimiento de teorías sobre el toyotismo, los Nuevos Conceptos de Producción de Kern y Schumann, la especialización flexible de Michel Piore y Charles Sabel, la teoría del industrial governance y su preocupación sobre las cadenas productivas, entre otras (de la Garza 1999).

Durante los años 90 surgió el concepto de identidad en el trabajo. Se enfatiza en dicho tema para demostrar que los procesos de trabajo van en detrimento de la clase trabajadora y que, con el tipo de actividades que se generan, las identidades se fragmentan y los sindicatos se debilitan. Al mismo tiempo, se hace hincapié en el tema de desregulación del trabajo, la flexibilidad laboral y la precarización, como procesos diferenciados que a la vez están vinculados.

En Costa Rica, varios estudios analizan y dan cuenta del proceso de deterioro de las condiciones de trabajo y empleo que experimentan cientos de costarricenses (Pérez Sáinz 1989, 1991, 1998, 1999, 2002; Trejos y Mora 1997; Trejos y Abdallah; 2000). Es un proceso que aún no ha concluido, y que ha tendido a enfatizarse ahora con amenazas aún más claras y determinantes, ya que se debate en la actualidad sobre cambios en el código de trabajo y, con ello, se cuestionan lo que en otro momento fue considerado y calificado como las conquistas históricas de la clase trabajadora.

El siglo XXI irrumpe la sociología del trabajo con nuevas perspectivas. Los optimistas se inclinan por el estudio de la manufactura y la maquila; de ahí que abunden los estudios sobre dicha actividad. Se enfatiza en el cambio del 
ensamble sencillo a las nuevas formas de organización y luego a la creación de conocimiento, enfatizando con ello en esa perspectiva optimista del trabajo y la nueva división internacional de este.

Aun así, el debate empírico se centra en mostrar cómo las empresas maquiladoras no siguen ese camino, el de la producción del conocimiento, sino todo lo contrario: se genera trabajo precario; el valor agregado es bajo; el proceso de producción es fragmentado; los insumos siguen siendo importados; la mano de obra no ha cambiado; son procesos de ensamble; y los sindicatos, cuando hay, son ficticios (de la Garza 2015).

La crisis del fordismo, con su desproletarización del trabajo industrial y deslocalización de la producción, trajo consigo la acumulación centralizada y concentrada del capital, por lo que era necesario hacerlo a partir de condiciones laborales precarias que explican una de las muchas expresiones de la desigualdad social. La precarización se traduce en la transformación de las relaciones sociales y de las subjetividades e identidades de clase (Antunes 2014). En este marco, es importante entender la precariedad como temporalidad, pues esta se deriva del proyecto de modernidad y el capitalismo, ambos avanzando a distintas velocidades, en diferentes direcciones y de formas no lineales.

Surge, pues, la necesidad de distinguir el concepto de precariedad del de la precarización; "la primera nace en un escenario donde se construye una América Latina neoliberal y se vincula a insatisfacción, escasez, fragilidad"; la segunda "hace referencia a un proceso temporal de degradación, pérdida, extensión y prolongación de la falta ordinaria" (Antunes 2014, 158).

Al ser así el panorama general y el contexto del que partimos, en este artículo tratamos el tema de las condiciones de trabajo, empleo y la corporeidad asociada desde la experiencia de trabajadores del sector de los servicios, en específico de los llamados call centers.

Los centros de llamadas son empresas en las que se pueden observar condiciones labores favorables como las que no cumplen con las normas de trabajo. Sin embargo, el texto que presentamos no analiza este aspecto; por el contrario, enfatiza en la vivencia cotidiana de quienes trabajan en los centros de llamadas y en cómo se sienten y cómo viven su experiencia laboral.

Los call centers son un sector de servicios que nos enfrenta a nuevos dilemas, razón por la cual coincidimos con Bericat (2004) en lo siguiente: en que hay trabajos que pertenecen a la posmodernidad porque son trabajos que enfrentan a las personas a nuevas tensiones y, sobre todo, por el sacrificio de lo que significa no tener fines de semanas libres, los días festivos o como le llamamos aquí "feriados"; son días de trabajo para la mayoría de las personas que trabajan en el sector de los servicios.

Los call centers no están excluidos; es la dinámica que demanda estar al servicio del mercado, del disfrute de otros en sus días de ocio, fines de semana libres y días de fiesta. Ello imposibilita a las personas compartir estos días que se caracterizan por estar con la familia, con las amistades y con la pare- 
ja; su tiempo libre es distinto. Por ello, es una actividad laboral en la que participan principalmente jóvenes, hombres y mujeres que por lo general no tienen hijos, jóvenes en formación que dicen de estar de paso. ¿Será siempre esta la norma? Estos y otros temas nos ha interesado indagar en dicho trabajo. Analizamos qué pasa por sus mentes, sus cuerpos y sus corazones, cómo se proyectan y que esperan de sí mismos, en el presente y en el futuro mediato.

\section{La experiencia laboral desde el cuerpo}

En este caso partimos de que la experiencia laboral se vive desde el cuerpo, puesto que es el medio desde el cual experimentamos la relación con el tiempo, el espacio y las emociones. El concepto del cuerpo que empleamos remite a la sociología de los sentidos, por ser un enfoque contemporáneo inclusivo; es decir, abarca la vivencia sensible de lo carnal, lo que Nick Crossley llamó "experiencia carnal" (1995, p.43); mientras que, la sociología del cuerpo hizo a un lado la respectiva experiencia sensible (Phillip Vannini, Dennis Waskul y Simon Gottschalk 2012).

Se estudia los sentidos corporales enfatizando en la experiencia emocional. Partimos de un cuerpo que siente y, por lo tanto, que experimenta desde lo sensorial y desde lo afectivo (Sabido Ramos 2012, 2016 y 2017); es un cuerpo que percibe a través de los sentidos corporales. Pero el cuerpo no percibe y vive la experiencia de forma neutra, hay experiencias que lo diferencia, Bourdieu (2000) nos invita a pensar el cuerpo desde la diferencia de género y Marx (1975) nos permite pensar los cuerpos desde la diferencia histórica y desde la clase social.

Desde el siglo XIX, Karl Marx planteó la relevancia de los sentidos corporales, más allá de la percepción individual, y puntualizó que "no existe una certeza "sensorial natural" pues los objetos que percibimos son "producto histórico"; los sentidos, así como las emociones son constructos históricos; las personas le damos contenido a la experiencia, la construimos. De ahí que retoma Sabido a Marx: "la formación de los cinco sentidos es la obra de toda la historia universal anterior" (Marx 1968, 121, en Sabido 2017, 63).

La producción capitalista no es ya producción de mercancías, sino que es, sustancialmente, producción de plusvalía (Marx 1975). Paulatinamente, con el modo de producción capitalista el trabajo que estaba en función de las necesidades básicas pasa a convertirse en mercancía y en valor de cambio. Por lo tanto, la fuerza de trabajo, que es el cuerpo, significa para unos una forma de subsistencia y mientras que para otros es la posibilidad de acumulación. Al ser el trabajador un sujeto explotado, es una persona no libre, está sujeto a sus condiciones de trabajo y opresión; desde esa condición vive de forma particular su experiencia sensorial.

El obrero es más pobre cuanta más riqueza produce, cuanto más crece su producción en potencia y en volu- 
men. El trabajador se convierte en una mercancía tanto más barata cuantas más mercancías produce. La desvalorización del mundo humano crece en razón directa de la valorización del mundo de las cosas. El trabajo no solo produce mercancías; se produce también a sí mismo y al obrero como mercancía, y justamente en la proporción en que produce mercancías en general (Marx 1976, 112).

En Marx el proceso que se genera con el capitalismo y su posterior desarrollo genera un sujeto que queda atrapado, alienado puesto que ignora su propia esencia y lo convierte en un fetiche. Pero la condición humana nos da otras posibilidades al del goce, aunque: "la actividad social y el goce social no existen, ni mucho menos, en la forma única de una actividad inmediatamente comunitaria" (Marx 1976, 11).

$\mathrm{Y}$, asimismo, nos señala aspectos claves que impacta[n] el pensamiento sociológico; el individuo es un ser social, forma parte de la totalidad, la totalidad ideal, la existencia pensada y sentida para sí" (Marx 1976, 12), la apropiación de la realidad humana. En el capitalismo, para Marx el placer queda subordinado al capital y el individuo que puede gozar lo hace subordinado al que capitaliza (Marx 1976). Es un aspecto que contrasta con Weber. quien analiza los procesos de cambio considerando el proceso sensorial y emocional de los sujetos.

Weber argumenta que el trabajo tiene un significado corpóreo y sensitivo para las personas desde el sistema capitalista. En el capitalismo tanto el trabajador como el empresario están sometidos a un doble sacrificio; porque el trabajo no está acompañado por un disfrute; sino, por el contrario, por una severa renuncia. El mundo en el capitalismo liga a la persona con la" acción" y la "renuncia" que se explica por el espíritu que acompañó al desarrollo del capitalismo, tesis central de su libro La ética protestante y el espíritu del capitalismo (Weber, 1999).

"El sudor del trabajo no viene acompañado por el disfrute de un mayor bienestar, sino por el sabor amargo de una severa renuncia" (Bericat, 2001:11). En ese sentido, Tawney, (citado en Bericat, 2001) señala que el doble y simultáneo sacrificio, necesario en el origen del proceso de industrialización, sentó las bases sociales de la acumulación originaria de capital, que posteriormente daría lugar al capitalismo.

Nos interesa destacar de las explicaciones de Marx y Weber que ambos autores relacionan el proceso de desarrollo del capitalismo con la vivencia corpórea, sensitiva y emocional de las personas, aspectos que posteriores estudios de carácter sociológico fueron dejando de lado. Actualmente, estas relaciones que establecieron ambos nos permiten construir un marco teórico que nos guíe en el análisis de los aspectos que hemos planteado en este texto, 
en torno a la corporeidad del trabajo desde la lógica del sistema económico que determina la experiencia del trabajador como tal.

Finalmente, señalemos que dicha experiencia corpórea del trabajo es factible desde un tiempo y espacio específicos, y determina las experiencias de las personas en sus relaciones y actividades. En esa línea, Simmel habla de la proximidad sensible, en tanto establece la relación que existe con respecto a tres elementos centrales: " 1 . Un cuerpo que percibe a través de los sentidos corporales, 2. Un cuerpo que está en relación con otros y 3 . Un cuerpo que está en un espacio específico".

(Sabido 2017, 250) establece tres categorías centrales para comprender las experiencias sensuales que conectan a los individuos (Sabido, 2017; Vannini, Gottschalk y Waskul, 2012). No cabe duda de que al ejecutar un trabajo en común, les permite a las personas relacionarse y resignificar su experiencia laboral desde lo individual y lo colectivo, al compartir tiempo y espacio en la realización de actividades. Así la actividad laboral les conecta, les acerca y les permita construir un nosotros, con más cercanía y fortalezas, o bien menor empatía y, por tanto, extrañeza. Aspectos en los que indagamos y de los cuales se da cuenta en este artículo.

\section{Condiciones de trabajo y condiciones de empleo}

Partimos de que para hacer un estudio que nos hable de la realidad y las percepciones de los trabajadores, debe ser abarcador, lo que se ha respetado en la investigación realizada, a pesar de que en este escrito se enfatice en pocos subtemas.

Sociológicamente, se sostiene que las "condiciones de trabajo" son una construcción multiactoral en la que convergen concepciones institucionales, empresariales, sindicales y de los trabajadores en una disputa cotidiana permanente que pretende acotarse por diferentes marcos jurídicos (Convenios de OIT, LFT, leyes locales de trabajo, contratos de trabajo y reglamento interior de trabajo) (Guevara 2005).

Hay relaciones de poder implícitas y explícitas que se manifiestan por medio de mecanismos de control ejercidos por la empresa y por las instituciones laborales dirigidas hacia el trabajador, quien, en tanto actor principal, acepta, tolera o cuestiona, muchas veces en desigualdad, sus condiciones laborales.

Las condiciones de trabajo, en la medida en que constituyen el referente de las situaciones de trabajo, son permanentemente objeto de evaluación. Dicha evaluación nunca podrá ser completa si queda solamente a nivel de la empresa o fábrica, dado que esa valoración se desarrolla dentro de un contexto social e histórico, el cual constituirá el último, pero a la vez el principal referente para su evaluación.

Por ende, las condiciones de empleo y trabajo son determinantes en la vida de las personas, con el fin de identificar cuáles aspectos inciden más en la cotidianidad las personas y cómo viven sus experiencias corporalmente. 
Analíticamente diferenciamos las condiciones de empleo de las condiciones de trabajo, aunque a veces nos referimos de forma generalizada e indiferenciada a ambos fenómenos. Entonces, señalemos que las condiciones de empleo hacen referencia a las circunstancias en las que una persona realiza un trabajo u ocupación, y están constituidas por una serie de garantías, derechos, compromisos y obligaciones -ya sea explícitas o implícitas- en las diferentes dimensiones e indicadores del trabajo que se establecen formal e informalmente, de manera colectiva o individual, entre el trabajador y quien lo contrata, y que determinan la situación que vive el trabajador o la trabajadora en su empleo u ocupación; aspectos que lo alteran o benefician en lo individual, familiar y social. En este caso, se analizan variables como tipo de empleo (fijo, estable o indefinido), horario (completo o parcial), tipo de contrato, calidad del empleo derivado del tipo de contratación, salario.

Las condiciones de trabajo captan las circunstancias en los centros de trabajo o bien en el lugar que se llevan a cabo, determinan la exposición a riesgos en el lugar de trabajo y el modo como éste está organizado (lugar de trabajo y organización del trabajo).

\section{Los servicios y la tercerización de la economía: la expansión de los call centers}

Según la Organización Internacional del Trabajo (OIT 2016), la inserción de América Latina y el Caribe (ALC) en las cadenas mundiales de suministros (CMS) ha llegado con rezago, con una participación más baja que otras regiones, y "el bajo valor añadido nacional (16\%), en comparación con el promedio de $28 \%$ de los países en desarrollo, sugiere que la participación general de las empresas y las/los trabajadores de América Latina y el Caribe tiende a concentrarse en las etapas con poco valor añadido de las Cadenas Mundiales de Suministros".

Los países de la región participan con diversos niveles de desempeño en cadenas con gran capacidad de generar empleo e ingresos, lo mismo que contribuir al Producto Interno Bruto (PIB). Entre ellas, se destacan: agricultura de alto valor, prendas de vestir, manufactura avanzada, industrias extractivas y servicios deslocalizados.

El desempeño depende de factores como la dotación de recursos, la distancia desde los mercados de destino, las barreras geográficas internas, el tamaño de los mercados, y el desarrollo y la orientación de las políticas públicas que promueven la inserción en estas cadenas productivas. En lo relativo a las cadenas de interés para nuestro estudio, Costa Rica tiene un desempeño notable en los servicios deslocalizados (outsourcing), pero no en la manufactura de poca tecnología, como la maquila textil.

Lo ideal es que la inserción de los países en el mercado internacional implique la mejora económica y social. La OIT, como organismo internacional, señala que las CMS deben promover el trabajo decente en la economía mundial, tema que se mantiene en el debate. La mejora económica es esencial para la creación de más y mejores puestos de trabajo; mientras que la mejo- 
ra social se relaciona con las normas y derechos laborales, así como con el acceso a la protección social (OIT 2016).

En particular, en nuestra investigación interesa precisar qué está ocurriendo en Costa Rica en el ámbito de la mejora social (social upgrading) para relacionar dicho indicador con la cotidianidad de la experiencia laboral de trabajadores de los call centers.

El concepto de mejora social en las CMS, según la OIT (2016), presenta tres elementos fundamentales: "(1) la generación de empleo, es decir la cantidad y la calidad de los empleos y sus implicaciones para la protección social; (2) la promoción, aplicación y mejora de la salud y la seguridad en el trabajo, los ingresos, la libertad de asociación, la negociación colectiva y demás derechos laborales; y (3) el desarrollo de habilidades, que permite que los trabajadores se adapten a los requisitos cambiantes en las CMS de nuevas capacidades, habilidades y conocimientos, y también facilita la movilidad de los trabajadores a etapas más difíciles y mejor remuneradas de la cadena".

Estos tres aspectos han sido considerados a la hora de indagar sobre las condiciones de trabajo y empleo de las personas entrevistadas; sin embargo, fijamos el interés principalmente en la vivencia emocional. Por esta razón hablamos de la corporeidad del trabajo, con el fin de captar las dimensiones físicas y emocionales de su experiencia.

Los call centers forman parte del sector terciario de la economía que despuntó con fuerza a partir de dos décadas atrás; de esta forma, los centros de llamadas toman un lugar central como generadores de empleo a nivel mundial. Ese crecimiento queda especialmente reflejado en los trabajos que aprovechan el conocimiento tecnológico propio de las tecnologías de la información y la comunicación (TIC) para la ampliación de servicios y la mejora de estos.

En un primer momento, se iniciaba la actividad ofreciendo comunicación bidireccional, aunque solo de voz; en la actualidad, los avances en hardware, software y redes de comunicación se han convertido en el motor de la evolución del centro de llamadas a los centros de servicios compartidos, que ofrecen más posibilidades en el campo de transmisión y procesamiento de datos o la estandarización de procesos.

En tal contexto se desarrollarían los denominados web-enabled call centers, que aparecen integrando la tecnología tradicional de los centros de llamadas con el empleo de internet para complementar el servicio prestado. En esta investigación se consideran tanto los call center como los web enabled call centers (Piedra 2018).

El call center constituye un centro de producción de telemensajes; la estructura organizacional se puede observar con las dimensiones típicas de un ensamble sociotécnico: proceso, organización y coordinación del trabajo. El proceso de trabajo consiste en una telenegociación entre una persona usuaria telefónica y el teleoperador. La comunicación puede ser iniciada por el primero (llamadas in bond) o por el segundo (llamadas out bond). 
Esta telenegociación puede tener la simplicidad de una cadena de opciones rutinarias (una compra de una pizza, de un boleto, la solicitud de una información, etcétera) o bien la complejidad de una atención a un cliente que requiere asistencia técnica o que va a plantear una queja o la compra o venta de pedidos de enseres para una empresa, asistencia técnica personal o para empresa, enlaces de comunicación para resolución de problemas técnico, etcétera.

En coincidencia con esta descripción general, en Costa Rica los call centers pasaron de ser solo un centro de llamadas de un servicio al cliente, con personal bilingüe, a centros más complejos; evolucionaron, y muchos de ellos se han convertido en centros de servicio compartidos o tercerizados. Roy Mena, director de asuntos corporativos de Sykes, nos explica que, en su esencia, los centros de servicios especializados siguen siendo call centers por el uso de esa tecnología en la atención, aunque actualmente ya se utiliza el correo electrónico, el chat o el sistema de tiquetes (Chacón 2006; Rodríguez 2008).

En los años noventa del siglo pasado los sportsbooks se instalaron; en el 2008 se llegó a reportar la presencia de 100 en el país, que incluían desde empresas pequeñas que contratan alrededor de veinte personas, hasta empresas grandes con alrededor de 500 personas empleadas (Chacón 2006; Rodríguez 2008).

Sin embargo, la evolución se dio de forma acelerada y se diversificaron; ahora, los centros de llamadas prestan labores a sus propias empresas en el mundo o a terceros que los solicitan globalmente, en áreas de tecnologías, en ciencias contables, en recursos humanos, de compras, de ingeniería y de diseño, aparte del software, los videojuegos, la arquitectura y la animación digital, con personal multilingüe (Coalición Costarricense de Iniciativas de Desarrollo, Cinde, y Cámara de Servicios Corporativos de Alta Tecnología CamSCAT 2017).

Entre las compañías de más renombre internacional que operan actualmente en Costa Rica se encuentran: Motorola, Amazon, Language Line, Western Union, Sykes, Infosys, Hewlett Packard, Concentrix, Intel y Supra Telecom. En el 2010, se llegó a reportar un total de 47 empresas de call centers que emplearon alrededor de unas doce mil personas en el país (Summa 2010); en el 2017 se reportaron 150 y se estima que generaron unos 30 mil empleos. Los reportes aún no son exactos; los datos que reporta Cinde se deben depurar para diferenciar desde el sector de servicios (sin turismo) cuántas personas se emplean en los call centers.

Hay que considerar que los call centers corresponden a una actividad que tiende a generar rápidos cambios, que constantemente se abren y cierran empresas, dependiendo de las posibilidades y mejores condiciones que ofrecen países de la región y otros continentes. Empero, quienes trabajan en este sector y han sido entrevistados, señalan que Costa Rica se ha posicionado internacionalmente en el mercado, que el dominio de varios idiomas, 
así como el nivel educativo de la mano de obra le permite competir contra otros mercados como el de La India y otros países de la región; adicionalmente, muchas empresas prefieren al país para el desarrollo de actividades más complejas como los centros de servicio compartidos o tercerizados (entrevista: Ricardo y Mariana).

Un buen ejemplo de evolución es el que plantea Mena, quien nos explica que un call center pionero en Costa Rica fue Acer, que era un centro de costo y daba servicio a los clientes. "Posteriormente, lo adquirió Sykes y lo transformó en un centro de generación de ganancias pues les da servicio a terceros (empresas) en diversas áreas, como soporte técnico y consultoría financiera" (Barquero 2017).

En esa misma línea, Vanesa Gibson, gerente de Clima de Inversión de Cinde, nos acota que "las empresas de centros de contactos que operan en el país han evolucionado junto al talento costarricense, desempeñando cada vez más procesos de mayor sofisticación y valor. Estas compañías son una importante oportunidad de empleo para jóvenes que van formando carrera, así como para gran cantidad de técnicos y profesionales, igualmente" (Barquero 2017). En el anexo 1 se presenta una lista de empresas de centros de llamadas que han estado operando en el país.

Es interesante notar cómo los relatos de las personas entrevistadas van de la mano con la forma en que se gestan y evolucionan los procesos de las empresas. Se presenta un dinamismo en los call centers que repercute en las personas, quienes aprenden a su vez a moverse y a buscar mejores opciones de empleo cuando surgen las posibilidades.

Por ejemplo, el 12 enero del 2010, WNS anunciaba la apertura de sus servicios en Costa Rica. Dicha empresa se dedica los servicios de tercerización del trabajo en áreas como servicio al cliente, legal, análisis e investigación y atención financiera a más de 215 empresas en el mundo (Chaves 2010).

En un artículo de periódico, se señala que la llegada de la compañía a Costa Rica responde a su deseo de expandir su red de contactos globales en Latinoamérica. Aunque WNS Costa Rica iniciará brindando sus servicios a clientes localizados en Estados Unidos, no se descarta la posibilidad de que en un futuro la atención también se dirija a empresas de otros lugares del mundo.

La cercanía geográfica con ese país norteamericano, la similitud de horarios y el recurso humano capacitado y bilingüe fueron los factores que se tomaron en cuenta para la apertura de operaciones en Costa Rica. Caribbean Airlines, Scandinavian Airlines, SITA, Travelocity, KLM y British Gas son algunos de los clientes más grandes de WNS a nivel mundial. Por ejemplo; Ricardo nos narra que él empezó a trabajar en WNS cuando se instaló; señala que no era una empresa muy grande:

Ricardo: "Tal vez podrían trabajar unas 200 personas; no sé qué se considera grande. Pero sí, bueno, tal vez 250 
personas distribuidas en diferentes turnos y en diferentes cuentas, porque había turnos nocturnos; por ejemplo, la gente que hablaba francés atendía Europa, Francia, ciertas partes de África y demás que llamaba gente desde, bueno...

Entrevistadora: Ajá, y entonces significa que no era solo para Latinoamérica... Es decir, vos estabas en la parte de América Latina y Brasil, ¿pero prestaban servicio a otras partes del mundo?

Ricardo: Sí, era global. Yo estaba en América Latina, Brasil y demás porque mi enfoque era el portugués, y el horario relativamente similar al horario que tenemos en Costa Rica. Sin embargo, había otros empleados que hablaban otro idioma; por ejemplo, francés, y atendían usuarios que podían, no sé, estar llamando de Francia, de un país en África de habla francesa, Canadá y demás.

Posteriormente, Ricardo se empleó en Infosys, que abrió el servicio desde el país en marzo del 2013; una vez que lo supo, no dudó en pasarse de empresa y actualmente sigue trabajando en el mismo lugar. Relata que, con el tiempo, la empresa se ha ido especializando y a él le ha permitido capacitarse, formarse en informática, que ya está a punto de graduarse y, por lo tanto, sus tareas son cada vez más complejas.

Sobre el mismo tema, de forma paralela en los medios de comunicación se informa que: "[l]a transnacional de consultorías Infosys inauguró hoy un nuevo centro de servicios tercerizados en Costa Rica donde ya emplea a cerca de 100 personas. Según un comunicado, difundido esta mañana, Infosys ofrecerá desde ese centro una serie de servicios de tercerización en Costa Rica para sus clientes globales en las áreas de finanzas y contaduría, recursos humanos, análisis, procesos legales, manejo de clientes, mercadeo, y manejo de encadenamientos" (Leitón 2013).

Constatamos a partir de la información obtenida, que quienes logran emplearse en un call center no se dedican exclusivamente al servicio al cliente, sino que atienden otras áreas relacionadas con los servicios tercerizados, tienen más movilidad y pueden escalar hacia otros puestos de trabajo, lo que les genera más retos, interés en la actividad que realizan y, por lo tanto, aunque reportan que su trabajo es muy estresante, obtienen su recompensa, 
puesto que su salario mejora y no siempre están haciendo la misma labor. De esta forma, la experiencia laboral y su experiencia sensitiva y corporal son más amigables; no viven las tediosas laborales del telefonista que trabaja atado a un espacio reducido y a un tiempo pautado; así que el sacrificio del que habla Weber (1999) se experimenta de forma diferenciada.

La movilidad laboral es un elemento que, al parecer, tanto para empleados como empleadores está claro, aunque ello implica que a veces las condiciones laborales varíen. Las empresas saben qué hacen y hasta dónde lo hacen, como lo expresaron Alejandro Arciniegas, gerente general de Sykes Costa Rica; Roy Mena, director de Asuntos Corporativos; y Flora Solera, vicepresidenta senior de Sykes América Latina en una entrevista para el periódico La Nación:

No esperamos que todos vengan y se unan a nuestra compañía y trabajen aquí para siempre; nos encantaría eso, correcto; pero no es práctico; necesitamos personas que puedan venir y unirse a nuestra compañía, y comunicarse con nosotros el tiempo suficiente para que obtengamos el retorno de la inversión que hicimos; pero [sic] nos encantaría ver que obtengan un retorno de la inversión que han realizado y que hemos hecho; y eso significa que tienen que ir y tomar un ascenso, ir a trabajar a otro lugar; nos sentiremos felices mientras digan: "Estoy muy agradecido con Sykes, porque no tendría el trabajo que tengo hoy, si no me hubiera unido a Sykes primero" (Leitón 2018).

Si contratamos a alguien y los entrenamos, y luego lo perdemos en 90 a 180 días, eso es lo peor; pero si los perdemos, tal vez dos y medio o tres años, también estamos decepcionados. Pero no es tan malo porque recibimos un retorno de ese individuo y creo que estamos construyendo nuestra marca cuando se vayan" (Leitón, 2018). 


\section{El trabajo como autorrealización o para la autorrealización}

En este trabajo se parte de un concepto amplio del trabajo en el que se considera tres dimensiones que pueden estar presentes en la acción humana: cognitivo-instrumental, práctico-moral y estético-expresiva (Habermas 1981). Se rompe con la perspectiva instrumental en la que el trabajo está destinado solo a la producción del valor de uso. Desde el enfoque instrumental, el trabajo no puede dar lugar a la construcción de autonomía, ni a la autorrealización individual (Noguera 2002).

Se intenta generar un análisis más integrado basado en una perspectiva feminista y marxista del trabajo. Significa que el trabajo no alude solo al trabajo productivo: reconoce el trabajo reproductivo, aunque la investigación centró su foco de atención en el trabajo remunerado, como la experiencia a partir de la cual se analiza la vivencia sensitivo corporal de las personas entrevistadas y encuestadas.

En este caso, partimos de que el trabajo se considera actualmente como una actividad humana orientada a la producción de los bienes y servicios necesarios para la satisfacción de las necesidades, pero que estas no están determinadas únicamente por el mercado. Por ejemplo, Schumacher (1980) parte de que para estudiar el trabajo se debe considerar tres dimensiones básicas: la productiva, la autorrealización y la socialización.

El trabajo se caracteriza por otras dimensiones sociales; mediante la coordinación y el intercambio, las actividades de trabajo de los individuos interactúan, estableciendo roles y funciones para la creación de bienes y servicios. En la definición de roles y funciones, las acciones técnicas inherentes al trabajo desarrollado se vinculan con un conjunto amplio de atributos y expectativas que definen el estatus del trabajo y otorgan derechos y obligaciones a quien lo realiza.

Así pues, "el trabajo no solo implica la producción de bienes y servicios, sino también el entramado de relaciones sociales que refleja las convenciones colectivas del modelo simbólico de trabajo construido en cada sociedad y cultura" (Gamst 1995: 9). El trabajo humano es un esfuerzo o una actividad energética física y mental que satisface un propósito y una utilidad dirigida hacia un objetivo con referencia a las modalidades de comportamiento de una cultura específica o una de sus subculturas, gracias al cual los individuos y grupos sociales obtienen los medios para el mantenimiento de la vida (Gamst 1995).

De acuerdo con la definición anterior, un primer elemento del trabajo humano es la aplicación de esfuerzos y el desarrollo de actividades físicas y mentales para ejecutar alguna tarea determinada. Un segundo elemento es la intencionalidad de la acción de trabajo y la utilidad del producto ${ }^{7}$. El tercer elemento es la relación del trabajo con la subsistencia humana y la reproducción social.

El trabajo está estrechamente relacionado con la adaptación humana al medio ambiente en su forma integral; esto es, tanto geográfico como sociocultural. La acción creadora del trabajo proporciona los medios para mantener la
7. La intencionalidad se refiere a que la acción de trabajo no es instintiva y se dirige a un fin específico; la utilidad, a que la acción de trabajo deviene en la creación de cosas de valor. La intencionalidad y la utilidad del trabajo le confieren a este otra dimensión social. El propósito de cualquier actividad, así como el valor de cualquier cosa, no existe objetivamente, sino que depende del punto de vista del observador: es definido culturalmente y varía dentro de cualquier cultura específica. 
vida, de acuerdo con los requerimientos biológicos y socioculturales que determinan los modos de vida que caracterizan a grupos sociales y sociedades específicas.

Sin embargo, teórica y vivencialmente ha tendido a prevalecer una idea reducida e instrumental del trabajo, que a la vez se ha fundamentado en la idea del trabajo como sacrificio, la renuncia al disfrute de este (Weber, 1999) y la actividad enajenante en que deviene la tal experiencia (Marx 1976).

Todas las personas entrevistadas señalaron la contrariedad que significa trabajar para vivir, para mantenerse, aunque persista a su vez la idea de que el trabajo también debería ser para realizarse. Este es un aspecto que refiere a un debate conceptual importante; en las narraciones de las personas se detecta y expresa claramente. El relato que a continuación presentamos, ilustra la temática que deseamos destacar (Miriam de 35 años, ha trabajado 16 años en varios call centers):

M: Bueno, para mí, trabajo es prestar un servicio a una persona o a una empresa, una compañía y a cambio recibir un salario... Ahora hay diferentes tipos de trabajos; están los que a la gente le gusta y los que no. Están los trabajos en que vos trabajás en algo que estudiaste y hay otros que trabajás porque necesitás vivir o porque mientras estás estudiando necesitás hacerlo, para poder generar un poco de dinero.

N: Ok. ¿Para vos qué rol juega el trabajo en la vida de las personas?

M: Muy importante porque sin trabajo no comés, no pagás tus gastos, la casa, la comida; la comida es como lo más importante, entonces es bastante importante, incluso para la gente que todavía no ha sacado la profesión o lo que sea, necesita tener un trabajo para poder terminar o sacar su profesión y es bastante importante, o sea; y aunque estés estudiando y no necesités estudiar, alguien de tu familia necesita trabajar para poder mantenerte, darte de comer; es bastante importante. (...) 
Pocas personas hacen un trabajo voluntariamente donde saben que no van a recibir dinero a cambio; y si ese fuera el caso, tiene que tener otro trabajo que realmente le genere para poder hacer este trabajo voluntario que no le genera, que tal vez es lo que más les gusta.

Desde esta perspectiva el trabajo se instrumentaliza; es un medio, pero no es un fin. Nos señalan los distintos relatos que el trabajo que realizan no forma parte de su autorrealización, pero es el medio que tienen para lograr otros objetivos personales, laborales y familiares. Se trata, pues, de un nudo teórico de la sociología que ha enfrentado a autores clásicos y contemporáneos, marxistas, liberales: ¿puede el trabajo ser para actividad generadora de sentido? Para responder a esta pregunta, hay que partir de que existen dos perspectivas de trabajo que inciden: nos referimos a la perspectiva amplia y a la restringida del trabajo.

Una perspectiva amplia del trabajo parte de que este contiene potenciales de autonomía y autorrealización. Marx definió el trabajo desde dicho enfoque amplio, a pesar de que se ha interpretado, reducido su análisis y parafraseado sus escritos de forma limitada y delimitada. Se suele enfatizar en el valor de uso de los bienes producidos y el proceso de enajenación que la relación trabajo-consumo implica.

Noguera (2002) señala que Marx no asumía una postura productivista como sí lo hacia el pensamiento liberal y burgués de su época. Y, a pesar de las diferencias en los contextos sociales entre el suyo y el actual, Marx nunca planteó la producción económica como un fin en sí mismo; por lo contrario:

la prioridad para él era el desarrollo humano, de tal manera que el ser humano, domine y controle la producción, en vez de verse controlado por ella (...) Su actitud claramente favorable hacia la reducción de la jornada y el aumento del tiempo libre documentan también su antiproductivismo (1872, 379). En este sentido, Marx definía la riqueza precisamente como tiempo libre y como autorrealización, no como consumo y acumulación (Noguera 2002, 151).

Desde esta perspectiva, lo ideal es contar con un trabajo que permita el desarrollo integrado de las personas, desde el trabajo libre y creativo, como un camino hacia la autorrealización. El esfuerzo y la autosuperación son viables en un trabajo en el cual la persona se siente identificada, gratificada, enrique- 
cida cotidianamente $y$, por lo tanto, realizada. Pero ante las limitaciones que existen para que las personas vivan tal proceso de crecimiento y ejercicio del trabajo libre, por lo general, las personas viven la instrumentalización.

Habermas es un claro exponente de ese enfoque, para quien la idea de Marx era romántica. Señala que la emancipación del trabajo se lograría reduciendo el tiempo dedicado al "trabajo-carga" a lo mínimamente necesario, y que no se debe apostar a un trabajo crecientemente autónomo y autorrealizatorio (Noguera, 2002).

Siguiendo esta lógica analítica, observamos cómo en los testimonios de 11 de las 12 personas entrevistadas, estas señalaron que, aunque se sentían bastante bien con el trabajo que realizaban, sobre todo por el salario y por la flexibilidad en cuanto a horarios, no aspiraban a permanecer indefinidamente en él porque es un medio para lograr otras metas, como dedicarse a su profesión o para el desarrollo de una empresa propia a mediano plazo.

Entonces, el trabajo para la mayoría de las personas encuestadas y entrevistadas es temporal, es un medio para; empero, a su vez, nos remite a otro aspecto que tiene que ver con el tipo de trabajo y con las condiciones de trabajo, que se han tratado en otras investigaciones, a saber: el tema de la temporalidad de la experiencia laboral, ya no observada desde el tema de la libertad versus la instrumentalización de la actividad, sino desde las condiciones laborales.

\section{La temporalidad: de la experiencia laboral y las condiciones del empleo en los call centers}

Desde la perspectiva de las empresas, de las personas empleadas y de varios estudios realizados en América Latina, los call centers son espacios laborales que privilegian la contratación de personas jóvenes, quienes no planean tener una larga trayectoria laboral en su lugar de trabajo. Y cuando hablamos de tener una corta trayectoria laboral, las personas lo remiten a experiencias que deberían reducirse a uno, dos o máximo cuatro años (Chacón 2010; Rodríguez 2008; Del Bono y Bulloni 2008; Lerrer, 2008; Santos y Marques 2006; Vargas 2015).

La empresa, por su parte, no persigue como fin la retención de sus empleados/as a pesar de la inversión que realizan en procesos de capacitación o de otros espacios de formación que se han desarrollado en el país, como el Instituto Nacional de Aprendizaje (INA), la Universidad Latinoamericana de Ciencia y Tecnología (ULACIT) y el Colegio Universitario Boston (Vargas 2015).

Aunque en la investigación realizada no se contó con una muestra de población que permita la generalización de la información primaria obtenida, en sus respuestas se constata que el objetivo de su trabajo en el primer call center al que ingresaron era transitorio, y que su deseo era permanecer allí por un máximo de dos años. También narran que, por lo general, no laboran en la misma empresa, pero su trayectoria laboral en este tipo de trabajo se 
ha extendido en algunos casos por más de quince años. Es un lapso no esperado; 15 de 17 personas encuestadas indican que su estadía en los call centers se ha extendido más de lo deseado.

La razón principal es el salario. La segunda, el tipo de actividad que tienen a cargo; es decir, con el tiempo el trabajo no es el mismo: se supera la etapa inicial y se asumen trabajos más complejos y de más responsabilidad. Finalmente, quienes logran escalar dentro de la empresa obtienen "su recompensa", supervisan procesos de trabajo, proyectos creativos y técnicos fuera del país.

Sin embargo, para las personas cuyo trabajo consiste solo en la atención al cliente en los centros de llamadas, la motivación y satisfacción no son tan amplias; sus jornadas de trabajo suelen transcender entre el estrés propio de la actividad que realizan y el deseo que cumplir con los estándares establecidos. Su experiencia corpóreo-sensitiva es negativa y constantemente se están enfermando, experiencia que viven personalmente y la observan en las otras personas.

Entonces, el trabajo deja de ser temporal y quienes eran jóvenes ya no lo son tanto. Hay dos grupos claramente diferenciados: los que tienen entre 18 y 24 años y los que tiene entre 25 y 38 años (pero en sus relatos nos cuentan que tiene compañeros de 50 años o más). Los mayores se distancian de los más jóvenes; consideran que ellos ya transitaron por el período inicial -el de la fiesta, el gasto excesivo del salario los fines de semana-, y, por el contrario, ahora viven de forma independiente, retomaron sus carreras y proyectan su futuro a mediano plazo fuera de empresa. Estos aspectos señalados se desmarcan de afirmaciones de otros autores que observaron a inicios del presente siglo que los call centers se caracterizaban por su flexibilidad laboral, que las personas eran principalmente jóvenes, flexibles y con trabajo transitorio (Sennett 1999 y Crovi 2000).

La actividad en general suele captar principalmente a personas jóvenes entre los 18 y 24 años. Pero ahora, estos jóvenes ahora son jóvenes adultos (de 25 a 35 o más años) y el trabajo no fue tan transitorio, como lo esperaban; llevan trabajando más de dos años y, en algunos casos, se ha extendido a más de 10 años y sin miras a dejar de hacerlo y la actividad en cuanto a horarios no es tan flexible, como se los plantearon a la hora de iniciar a trabajar. La flexibilidad se reduce a seleccionar el turno de trabajo que más se ajuste a sus necesidades, pero no siempre lo logran.

Hay, así, un sentimiento de estar atrapado, en el tiempo, puesto que su actividad cotidiana está pautada por sus estrictos horarios de trabajo y porque la temporalidad de su permanencia se ha alterado. De nuevo, sus desencuentros con lo deseado, se refleja en su cuerpo sensitivo que muchas veces estalla en crisis continuas de ansiedad, cuando no pueden contenerla y controlar la angustia. 


\section{La contrariedad: tengo buenas condiciones de empleo y me siento mal}

Considerando lo antes expuesto, refirámonos ahora a las condiciones de para analizar las desigualdades en la salud; en nuestro caso, se enfatiza en las condiciones de empleo.

Al hablar de las condiciones de empleo, observamos que el empleo en los call centers no necesariamente promueve la precariedad laboral, al menos en primera instancia; y las que estudiamos o captamos en el estudio de forma mayoritaria. Las variables que se estudian para identificar la precariedad son: el tiempo del contrato, si es por tiempo indefinido o no; el seguro social y si cuentan con derecho a vacaciones, etc. (Mora, 2011). Por el contrario, la mayoría reportó condiciones estables y contrato indefinido (ver cuadro 1)

\section{Cuadro 1. Condiciones de empleo reportada por los trabajadores de} los call centers

\begin{tabular}{lcc}
\hline \multicolumn{1}{c}{ Variables } & Si & No \\
\hline Cuenta con contrato & 17 & \\
Vacaciones pagadas & 17 & \\
$\begin{array}{l}\text { Pensión de jubilación } \\
\text { Acogerse a la incapacidad médica, sin problemas, }\end{array}$ & 17 & 1 \\
$\begin{array}{l}\text { cuando lo necesita } \\
\text { Permiso para ausentarse del trabajo para ir al médico }\end{array}$ & 16 & \\
$\begin{array}{l}\text { cuando lo necesita } \\
\text { Pedir un día de permiso por motivos familiares o }\end{array}$ & 16 & \\
personales, sin problemas, cuando lo necesita & 17 & \\
$\begin{array}{l}\text { Permiso de maternidad/paternidad } \\
\text { Permiso de lactancia materna }\end{array}$ & 17 & 1 \\
$\begin{array}{l}\text { Cuenta con seguro social } \\
\text { El contrato es indefinido }\end{array}$ & 16 & 1 \\
\hline
\end{tabular}

Fuente: elaboración propia con base en la encuesta: Condiciones de trabajo y empleo en la maquila textil y los call centers.

En un contexto en el cual la globalización ha inducido el declive relativo del empleo público, la precarización de las relaciones salariales, la empleabilidad como la nueva utopía laboral del (neo)liberalismo y la emergencia del desempleo estructural (Pérez Sáinz 2014), se puede afirmar que en los call centers, las personas que laboran, por ser en su mayoría, aunque no exclusivamente, gente joven, tienden a contar con mejores condiciones de trabajo que lo que se ofrece en un empleo informal $u$ otras actividades.

Es un trabajo que, por lo general, les permite obtener buen salario, aunque varía de acuerdo al tipo de call center al que se ingresa y a la actividad que se le asigna. La ventaja de este trabajo es que no requiere contar con un título universitario o técnico, pero sí un dominio aceptable de algún idioma, el in- 
glés es el más común; pero actualmente, mientras más idiomas conozca, las opciones laborales mejoran significativamente.

Miguel: Siento que ... hay muy, muy buenas condiciones laborales; es un lugar muy seguro. Las instalaciones están muy bien capacitadas. A todos los empleados de la empresa se les da un seguro privado, o sea, por fuera de la Caja [Costarricense de Seguro Social]; entonces, si estás enfermo, si tenés que ir al dentista o cualquier eventualidad relacionada a la salud, está cubierta por ese seguro... Los equipos que uno usa están en muy buenas condiciones y los lugares de descanso son cómodos. Hay muchos microondas, muchas neveras; entonces uno como empleado sí puede sentirse muy cómodo en cuanto al área de trabajo y los alrededores.

Los aspectos antes señalados nos permiten afirmar que la flexibilidad en los call center se vincula con las necesidades productivas y funcionales de las compañías, más que con las capacidades que puedan desarrollar sus trabajadores. Coincidimos con Lerrer (2008), quien destaca que estos espacios laborales presentan características neo-tayloristas como "la sumisión al tiempo y la estructura de los softwares, el control racional del tiempo y del trabajo por medio de la informática; la productividad máxima en detrimento de las buenas condiciones físicas y psicológicas de los trabajadores" (Lerrer 2008, 7).

Será por ello que las personas se sienten mal, pero a la vez les genera la contrariedad de: "¿Por qué?, si cuento con buenas condiciones de empleo." Podríamos pensar que es un sentimiento contradictorio; aunque no lo es tanto si consideramos que los call centers representan la maquila de la nueva organización del trabajo a nivel internacional, a pesar de ser una actividad económica de punta que representa a las sociedades posindustriales.

Además, la tercerización es un elemento esencial que posibilita los encadenamientos tecnoproductivos y globales, y que, en contraste con otras actividades productivas, se contrata a personas con alto nivel educativo, en el que se requiere el uso de las tecnologías de la comunicación de punta. El siguiente testimonio da cuenta de las contrariedades, las dificultades y los sentimientos de quienes trabajan en el nivel básico:

Era frustrante, además, que para mí era demasiado res-

trictivo. Se siente uno como un autómata; o sea, vos te- 
nés tu computadora, hacés tu trabajo, pero no tenés nada a mano, no podés tener un teléfono, no podés meterte a ver La Nación (periódico local), no podés hacer absolutamente nada, ni siquiera en break. Entonces, es nada mas como siéntese y es llamada, tras llamada, tras llamada, tras llamada, tras llamada. Era como una autómata de verdad, te lo juro; a mí ese trabajo no me gustó. Lo que yo hacía sí, de interpretar y todo, ¿verdad?, de inglés a español, español a inglés, eso es un reto, es algo nuevo; pero en sí todo lo demás no (Melissa, 25 años).

Las empresas de servicios extraen de sus trabajadores aspectos de gran valor: juventud, energía, conocimientos y deseos de superación. Y aunque las condiciones de empleo no sean contrarias, como lo mencionamos anteriormente, no significa que sean siempre justas; más de la mitad de los testimonios de las personas entrevistadas relata dicha situación (siete de once casos):

Tal vez tener que hacer tantísimas cosas porque son demasiadas cosas que una persona tiene que manejar y no tener una compensación monetaria por todos los dolores de cabeza; porque sí me parece como muy injusto tener que hacer todo lo mismo que una persona que está a la par mía y que esa persona gane 650mil colones más y yo estoy ganando, yo aquí a la par ganando solo 420mil colones; o sea, en el mismo puesto; o sea, en el mismo puesto, pero al no ser oficial, estar a la par y no ganar lo mismo es frustrante; pero no sé, en un principio no lo veía así tan mal... El punto es como tal vez sentir que ese valor no se le está dando al trabajo... me hace sentir mal, muy mal... (Gendry, 23 años).

El malestar de quienes trabajan no se centra solo en el hecho de si el salario es el justo, pues ese tema genera sentimientos de molestia e indignación. Esas emociones se manifiestan corporal y emocionalmente: somos cuerpos con emociones, por lo que uno y otro aspecto interactúan. Evidentemente, las personas encuestadas manifestaron sentimientos y sensaciones distintas; 
prácticamente, la mitad se sentía bastante bien y conforme, mientras la otra parte ha manifestado sensaciones de disgusto y malestar. El siguiente cuadro muestra dichos sentimientos encontrados entre quienes dicen sentirse bien y quienes no lo hacen:

\section{Cuadro2. Estados de ánimo con respecto al trabajo}

\begin{tabular}{|c|c|c|c|c|c|c|}
\hline Preguntas & $\underset{\mathrm{e}}{\text { Siempr }}$ & $\begin{array}{l}\text { Muchas } \\
\text { Veces }\end{array}$ & $\begin{array}{l}\text { Algunas } \\
\text { veces }\end{array}$ & $\begin{array}{l}\text { Solo } \\
\text { alguna } \\
\text { vez }\end{array}$ & Nunca & Total \\
\hline $\begin{array}{l}\text { Me gustan las labores que } \\
\text { realizo en mi trabajo }\end{array}$ & 2 & 7 & 6 & 2 & & 17 \\
\hline $\begin{array}{l}\text { Las labores que realizo en } \\
\text { mi trabajo son aburridas }\end{array}$ & 5 & & 9 & 3 & & 17 \\
\hline $\begin{array}{l}\text { Me siento motivado/a para } \\
\text { ir a trabajar }\end{array}$ & 2 & 6 & 6 & 1 & 2 & 17 \\
\hline $\begin{array}{l}\text { Las actividades que realizo } \\
\text { en el trabajo son } \\
\text { monótonas }\end{array}$ & 4 & 5 & 5 & 1 & 2 & 17 \\
\hline $\begin{array}{l}\text { Me gusta el ambiente } \\
\text { laboral en el que me } \\
\text { desenvuelvo }\end{array}$ & 4 & 5 & 7 & 1 & & 17 \\
\hline $\begin{array}{l}\text { Tengo buenas relaciones } \\
\text { con mis compañeros de } \\
\text { trabajo }\end{array}$ & 10 & 3 & 3 & 1 & & 17 \\
\hline $\begin{array}{l}\text { Tengo buenas relaciones } \\
\text { con mis superiores }\end{array}$ & 10 & 1 & 3 & 3 & & 17 \\
\hline
\end{tabular}

Fuente: elaboración propia con base en la Encuesta: Condiciones de trabajo y empleo en la maquila textil y los call centers.

Contrastan las opiniones entre quienes viven su trabajo desde la monotonía y se sienten poco motivados y quienes se sienten bastante motivados e interesados en su trabajo. Sin duda, cuando observamos de dónde proviene cada opinión, está relacionado con los puestos de trabajo y los salarios. Quienes se encuentran en el nivel más básico de atención al cliente, por lo general, muestran poca motivación, sin ser la totalidad; también hay quienes opinan que las buenas condiciones de empleo son un factor de estímulo suficiente para sentirse bien. En efecto, si contrastamos cuánto ganan, aunque estén en la misma empresa y en el mismo puesto, la diferencia salarial es de un poco más de 100.000 colones entre una persona y la otra. Antonio nos contaba que él gana por lo general unos 350.000 colones al mes, pero que hay compañeros que, en su mismo puesto, por colocar ventas, llegan a ganar al mes hasta 900.000 colones:

hay maes que se han ido con un salario mensual como de 900 mil colones, por las ventas... Yo lo veo como un trabajo mediocre. Entonces, eso me genera como, diga- 
mos, angustia. Lo que me gusta es eso: la flexibilidad. De que yo me pueda ir cuando me dé la gana. O sea, yo estoy consciente de que no estoy cortando caña para sostenerme... Es un trabajo que me gusta porque cuando quiero pido permiso y me retiro por días para hacer otras actividades de interés (Antonio, 34 años).

Cuadro 3. En el último mes ¿cómo se ha sentido en su trabajo?

\begin{tabular}{ll}
\hline \multicolumn{1}{c}{ Emociones positivas } & \multicolumn{1}{c}{ Emociones negativas } \\
\hline Bien (2) & Aburrido \\
Genial (2) & Estrés regular \\
Estable & Indispuesto \\
Tranquilo & Agotado \\
Muy satisfecho y contento & No muy bien \\
Excelente & Mal \\
& Inconforme \\
\hline
\end{tabular}

Fuente: elaboración propia con base en la Encuesta: Condiciones de trabajo y empleo en la maquila textil y los call centers.

Ambas sensaciones, malestar o bienestar, provienen de la cotidianidad, de la interrelación, de las relaciones, de las condiciones de empleo y trabajo y de sus expectativas personales. Sin embargo, las manifestaciones emocionales expresadas por los entrevistados tienen un contenido social y aluden a diferentes posiciones de estatus y poder (Kemper 1989 y 1978), así que "las emociones emergen de la combinación de ciertos elementos «externos» no controlables por los individuos (involuntarias) - con otros «internos» provocados o buscados por los individuos (voluntarias)" (Oliveira, 2016).

Se trata, en suma, de un juego relacional en donde existe una estructura social de carácter desigual basada en posiciones relacionadas con el poder y el estatus. Las personas cuentan siempre con menos o más poder y estatus. El juego interaccional que observamos en las manifestaciones de las personas entrevistadas, en términos de poder y estatus, determina las emociones que evocan los sujetos y oscilan, por lo tanto, entre la satisfacción y el rechazo a lo que ellas hacen o a su circunstancia.

Bericat (2000, 2012 y 2014) menciona el aspecto del status de las emociones como un factor importante en el análisis de las emociones y, retomando autores como Kemper, establece un índice de bienestar socioemocional. Por consiguiente, establece cuatro dimensiones: 1. status (comprende estados emocionales como la tristeza, la depresión y la soledad); 2. situación (capacidad de disfrute, felicidad); 3. persona (orgullo, optimismo); y 4. poder (tener la sensación de sentirse descansado, tranquilo o calmado y con energía). 
Si consideramos estas dimensiones, observamos cómo las personas entrevistadas señalan la presencia de todos los estados emocionales; queda pendiente establecer cuál de las variables tiene más peso. Si aplicamos la regresión lineal múltiple, se podría determinar la variable que explica o influye principalmente en el estado de ánimo de las personas.

Los sentimientos negativos que exteriorizaron las personas también se expresan corporalmente y se manifiestan como malestar físico, como nos relatan varias de las personas entrevistadas:

Dolor de cabeza. Eso es cuando hablan mucho, cuando ya han estado haciendo muchas horas extras en la semana $O$ ya no pueden hablar; entonces, se les va la voz. Y lo que uno hace en esos momentos para que ellos no pierdan el dinero de la incapacidad, uno los pone de apoyo, ellos andan ahí contestando preguntas... A los que son capaces de hacerlo; no todos pueden responder preguntas para todo.

Dirás que me costó mucho; yo soy epiléptico. Y en parte por eso dejé ese puesto gerencial alto porque estaba convulsionando demasiado; el estrés me estaba afectando, pero es por situaciones de empresa, ¿me explico? Es porque la presión del cliente es demasiada y si no se cierra el pago, son cientos de miles de dólares de penalización para la empresa, cientos de miles de dólares. Entonces, todo eso carga con su performance, con su rendimiento y al final del día es muchísima más presión lidiar con ese nivel de pérdidas que lidiar con un cliente que te esté gritando (Danilo, 30 años).

Bueno, me incapacitaron por 5 días, creo, y la otra por dos días. La primera vez era cuando era gerente de equipo; yo no le dije a nadie que era por eso; a todos les dije que era por asma... Técnicamente yo fui a la doctora porque pensé que tenía asma, me faltaba mucho el aire y estaba muy agitada y fui a pedir pastillas para dormir por- 
que no estaba durmiendo y, cuando entré, como yo le tengo a ella mucha confianza, simplemente me puse a llorar, y yo lloraba y lloraba y le decía: "Es que no puedo, no puedo, no lo logro, no lo logro, no lo logro" y ella me dijo: "No, pues, váyase para su casa; usted está mal; no debería estar aquí", y me incapacitó por ansiedad porque yo no aguantaba (Gendry, 23 años).

Finalmente, sobre el mismo tema es preciso señalar que quienes tendieron a sentirse mejor con respecto a su trabajo, a pesar del cansancio o agotamiento por exceso de trabajo, y que también expresaron sentimientos de satisfacción y orgullo fueron las personas que en escala salarial y tipo de responsabilidad laboral tenían $\mathrm{m}$ más estatus y reconocimiento social, estaban en puestos de dirección, gerencia y obtenían retribuciones propias de su posición; asimismo, realizaban tareas más creativas, podían proponer y resolver problemas asignados y tenían acceso a viajes de capacitación o coordinación.

\section{La cultura de los call centers, ser parte de y compartir espacio y tiempo}

Por otra parte, en la mayoría de las entrevistas realizadas fue notable que las personas sienten orgullo y satisfacción por el trabajo realizado, aunque a veces se refieran a él de forma despectiva. Hay un nosotros presente en sus relatos, que se refiere a lo que tienen en común a pesar de sus diferencias: sus vivencias, el estrés generado por el trabajo, sus turnos, el consumo de drogas, el sentirse diferentes a los demás y que no son empleados de cuello blanco, etcétera. Se alude a la subcultura compartida: "somos diferentes", "somos más libres", "no hay formas correctas de ser", "no me juzgan por la forma en que visto", "las personas me aceptan tal como soy", "no tengo que ocultar mi opción de género o sexual" o "no hay chismes porque soy lesbiana".

Aunque dos personas sí hablaron de la estigmatización de la que eran objeto, sin ser necesariamente correcta: "nos estigmatizan", "mucha fiesta, muchas drogas, pero no todo es así". Entonces, pregunto: ¿es real o es un "mito urbano"?, ¿existe una subcultura relacionada con el tipo de trabajo que realizan? (Denis, 30 años, supervisor de ventas y servicio al cliente):

D: Sí, por lo general somos muy agringados, muy transculturados [sic], diría yo, la mayoría. Muy en su cultura pop.

$\mathrm{N}$ : Y con respecto al trabajo, ¿cuál es su actitud? 
D: Al trabajo, hay menos compromiso. Pero sí hay una subcultura de call center, claro.

$\mathrm{N}$ : ¿Y en qué consiste?

D: El idioma marca mucho: se sienten muy cómodos o muy cool hablando en inglés todo el día. Es algo que, si no lo has hecho, no tenés la perspectiva de qué es el día a día, estar lidiando con estos gringos en el teléfono todo el día; entonces. los que sí lo han visto se siente acuerpados entre sí [sic] y por ahí va la subcultura. Pero como que tengan características específicas, no. Aparte de gastones y que les gusta lo bonito, no veo un patrón que sigan todos.

$\mathrm{N}$ : $\mathrm{Y}$ vos que sos supervisor, ¿qué pasa con el tema del uso de las drogas? ¿Lo ves en la gente? ¿Cómo se controla?

D: Sí. En la empresa hacen antidoping, por ejemplo. Hacen doping en la entrada, pero no más. Lo que yo veo que más consumen es alcohol, tabaco y marihuana en los call centers, y no necesariamente durante horas laborales todas; pero sí hay gente que ha llegado bajo las influencias de sustancias al trabajo. Hay gente que va así casi que, a diario, uno los ve siempre con los ojillos despistados, pero no es un tema, diría yo, principal o fundamental en la industria... No creo que le afecte muchísimo en su rendimiento; lo digo porque los he visto; no hago nada al respecto, pero yo no lo recomendaría tampoco. (..)

Es una forma de enfrentar el estrés, la ansiedad. Si la persona puede controlar la sustancia bien, me imagino 
que sí le ayuda; porque si no viene como un neurótico y o un psicótico, no sé, le puede afectar más bien.

Es muy interesante notar cómo este aspecto se relaciona con lo señalado por Scheff: los diferentes vínculos se van configurando según la combinación de dos categorías esenciales: el distanciamiento y el acercamiento; de manera que cuando el individuo consigue mantener un equilibrio entre ellas en su relación con otro individuo, o con un grupo de individuos, se forma aquello que Scheff (1990 y 2011) designa un «vínculo social seguro». Gendry lo expresa de esta forma cuando se le pregunta: ¿qué la identifica más con sus compañeros?:

Que cada uno tiene como su historia difícil... Entonces, tener esa conexión personal a nivel grupal y entre personas genera un vínculo muy diferente que lo que se genera en otros lugares; y eso es parte del ambiente que está ahí, el estar vacilando, el cómo uno se abre con las personas ahí es muy diferente... O sea, el ambiente, las risas, cómo a veces es un ambiente muy pesado cuando hay visitas o cosas así; uno lo siente muy pesado porque uno sabe la tensión que implica que venga gente de otro lugar, otro país a verlo: pero cuando no, es divertido estar vacilando (Gendry).

El vínculo social seguro es «la fuerza que mantiene a la sociedad unida» Scheff (1990 y 2011), o bien se refiere a un grupo unido, personas que forman parte de un "nosotros". Sin embargo, en dichos procesos sociales se puede producir un desequilibrio si existe hay demasiada proximidad o demasiada distancia. Ahora bien, dicho equilibro no es fruto de la igualdad de opiniones y posturas vitales de los individuos, sino que se puede lograr también gracias a la comprensión y conciencia de los desacuerdos y puntos de vista comunes.

En su modelo teórico, por tanto, el orgullo y la vergüenza, en la medida en que manifiestan la dimensión emocional de las categorías esenciales de distanciamiento y acercamiento, constituyen emociones fundamentales para determinar la naturaleza de los vínculos sociales. No es que estas sean las únicas emociones, sino que, según Scheff, 
están en la base de todo vínculo propiamente social (Oli-

veira 2017,60$)$.

Así, cuando una persona se siente orgullosa de un vínculo, significa que se determina a sí misma y por medio de los ojos de los otros, de forma positiva.

Ese tipo de valoraciones las apreciamos en los entrevistados; apreciaciones más positivas que negativas de su paso -permanente o transitorio- por los call centers.

\section{Reflexión final}

Expuestos los argumentos anteriores, solo nos resta señalar de forma concisa algunos de los hallazgos del trabajo.

Primero: destaquemos que la temporalidad del trabajo en los call centers no es una realidad que se constante en este estudio. Todo lo contrario: las personas ingresan jóvenes, con la idea de una permanencia temporal de corto plazo, pero suelen mantenerse allí durante periodos prolongados, más de lo esperado y deseado. Hay personas que cuentan ya con quince años de estar en el sector de los servicios de llamadas descentralizadas y tercerizadas. Se mantienen porque es un trabajo bien remunerado; igualmente, a veces, no cumplen sus metas académicas y ello les impide emplearse en buenas condiciones laborales en otras actividades remuneradas. Otras personas permanecen porque han desarrollado una experiencia laboral que les ha permitido desarrollarse en distintos espacios, formarse en aspectos técnicos y creativos, fijarse nuevas metas y mejorar sus condiciones de empleo.

Segundo: la mayoría de las personas entrevistadas, a pesar de no ser ya tan jóvenes, permanecen solteras y sin hijos; solamente uno de los entrevistados tiene una hija. Sin embargo, no es posible concluir de ello que las prioridades, al menos de las personas aquí entrevistadas y/o encuestadas, no sean la conformación familias o la formalización de relaciones de parejas.

Tercero: tenemos que las condiciones de empleo y trabajo no tienden a la precarización, aunque cuanto más pequeña sea la empresa, las condiciones de empleo tienden a desmejorar; en uno de los casos, las vacaciones y el seguro social no formaban parte del contrato de trabajo.

Cuarto: aunque se reportan diferencias en el tipo de contratación y las condiciones de empleo en los call centers, solo en uno de los casos, que corresponde a un call center pequeño, se reportó presencia de algunas variables que se utilizan para identificar la precariedad laboral en los trabajos.

Las buenas aceptables condiciones de trabajo que reportan los entrevistados en las empresas en las que laboran contrastan con la vivencia cotidiana, el estrés que ocasiona el trabajo que realizan, que conlleva efectos en su salud e induce a algunos al consumo de sustancias psicotrópicas, tabaco y alcohol para sobrellevarlos. Un factor positivo es el sentimiento de "nosotros" que se construye, al generarse diferencia y distancia con "los otros" que no los com- 
prenden y que no cuentan con las libertades que ellos tienen; esto permite conformar un colectivo basado en emociones positivas que contrastan con la estigmatización social de la cual son "victimas", un aspecto que refuerza su idea de comunidad.

Entonces, retomemos un punto plateado teóricamente que tiene que ver con el valor del trabajo, la identificación, el goce, la insatisfacción de los efectos en la salud de las personas. Las personas entrevistadas, en su mayoría, expresaron sentimientos de satisfacción con su trabajo, producto del elemento central del salario que obtienen; y como segunda opción, nuevas metas laborales que les demanda la ejecución de otras actividades, retos técnicos y ascenso en el puesto de trabajo, que implica incluso ocupar otro puesto.

Asimismo, se evidencia la construcción de procesos identitarios, una comunidad que se comporta de cierta forma y desarrolla actividades fuera y dentro del trabajo que los distingue de otras personas, trabajadores y compañeros de estudio. También hay un alto nivel de consumo y actividades hedonistas que su condición laboral y remuneración les permite.

Pero, a la vez, señalan factores negativos que tiene que ver con su experiencia emocional y sensitiva. No valoran el trabajo, el valor que le dan a la actividad que realizan en baja; salvo en los casos, los menos, que desarrollan actividades de tipo creativo, por el reto y desarrollo continuo. De esta forma, su trabajo es grato, aunque les genere agotamiento físico, mental y poco tiempo para estar con sus familias.

Así que quienes están en el nivel básico, atendiendo llamadas, consideran que su trabajo tiene poco valor, y no se sienten identificados con este, les produce rechazo y deseos de irse. Prevalecen sentimientos negativos, de rechazo, que se traducen en dolencias físicas que se relacionan con malestares psíquicos, además de un alto nivel de estrés que enfrentan cotidianamente en sus puestos de trabajo. Se genera así una contrariedad: por un lado, sentimientos de satisfacción y, por otro lado, de rechazo e insatisfacción.

En su día a día, hay una experiencia emocional muy fuerte: pasan pensando no en lo que puedo hacer desde mi trabajo para estar mejor o sentirme mejor; sino pensando en cuándo me voy a ir, lo que voy a hacer cuando me vaya y reafirmando que su trabajo es una experiencia de paso.

\section{Bibliografía}

Barquero, Marvin. Costa Rica hospeda alrededor de 150 centros de llamadas de empresas. 3 de julio 2017. Acceso 20 enero 2019. https://www.nacion.com/economia/negocios/costa-rica-hospedaalrededor-de-150-centros-de-llamadas-de empresas/ 
Bericat Alastuey, Eduardo. "Max Weber o el enigma emocional del origen del capitalismo" En: Reis Revista Española de Investigación Sociológicas. 95/01 julio-septiembre 2001. Pp. 9-36.

Bericat Alastuey, Eduardo. "Matrimonio, desigualdad de género y bienestar socio-emocional de los miembros de la pareja", en Adriana García y Olga Sabido (Coord.), Cuerpo y afectividad en la sociedad contemporánea, pp.191-228. México: UAM, 2014.

Bericat Alastuey, Eduardo. El contenido emocional de la comunicación en la sociedad del riesgo. España: Reis, 2013.

Bericat Alastuey, Eduardo. 2004. "El trabajador de fin de semana en la sociedad del ocio Tiempo de trabajo y calidad de vida en el sector servicios". Revista Internacional de Sociología, n. 38 (2004): 61-99.

Bericat Alastuey, Eduardo. "La sociología de la emoción y la emoción en la sociología" Papers n. 62 (2000): 145-176. doi.org/10.5565/rev/papers/ $\underline{\mathrm{v} 62 \mathrm{n} 0.1070}$

Bourdieu, Pierre. La dominación masculina, Barcelona, Editorial Anagrama (1era Ed. 1998), 2000.

Castillo, Didimo; Baca, Norma; Todaro, Rosalba. Trabajo global y desigualdades en el mercado laboral. México: Universidad Autónoma del Estado de México Facultad de Ciencias Políticas y Sociales, 2016.

Chaves, Vanesa. Wns abre operaciones en Costa Rica. Martes 12 enero, 2010. Acceso 21 de 2019. https://www.larepublica.net/noticia/wns_abre_operaciones_en_costa_ric a

Crossley, Nick. (1995), «The elusive body and carnal sociology MerleauPonty», en Body \& Society, 1(1), pp. 43-63.

Csordas, Thomas. (2011), «Modos somáticos de atención», en Cuerpos plurales. Antropología de y desde los cuerpos, Buenos Aires, Biblos.

De la Garza, Henrique (ed.). Los estudios laborales en América Latina. Orígenes, desarrollo y perspectivas. Anthropos, México, 2016 
De la Garza, Henrique. Panel: Balance y Revisión Crítica de los Estudios Laborales en América Latina. Conferencia pronunciada en el Congreso Latino Americana de Sociología ALAS-Costa Rica", 30 de noviembre 2015.

De la Garza Toledo, Enrique. "Trabajo y la vida a comienzo del siglo XXI" ponencia presentada en el seminario en la Universidad Complutense de Madrid. Los Estudios Laborales en América Latina al inicio del siglo XXI. Junio 2007, España.

Gamst, Frederik C. "Considerations of Work", en Frederik C. Gamst (ed.), Meanings of Work. Considerations for the Twenty-First Century por Frederik C. Gamst, 1-45. Nueva York, State University of New York Press, 1995.

Kemper, Theodore D. Toward a Sociology of Emotions: some Problems and some Solutions. The American Sociologist, n. ${ }^{\circ} 13$ (1978) 30-41.

Kernberg Friedemann, Otto, Relaciones amorosas Normalidad y patología. Argentina, Paidós, 1998.

Leitón, Patricia. "Infosys inicia su operación en Costa Rica con 100 trabajadores", La Nación, 11 marzo 2013, acceso el 10 enero 2019, https://www.nacion.com/archivo/infosys-inicia-su-operacion-en-costarica-con-100-trabajadores/ERCLBTYDFFDHRNEGS2DEJXRY7Q/story/

Leitón, Patricia "Presidente de Sykes: vemos una evolución hacia trabajos más técnicos y creativos en Costa Rica", La Nación, 11 marzo, 2018, acceso 20 de enero 2018, https://www.nacion.com/economia/negocios/ presidente-de-sykes-vemos-una-evolucion-hacia/

GJLTCME7ZNEOHDMGZO5RMO536Y/storyl

Lerrer, Cinara. "Construção da identidade no trabalho em call centers: a identidade provisória" Conferencia pronunciada en XXVI Congreso Asociación Latinoamericana de Sociología, 18 de agosto de 2007. Universidad de Guadalajara, México https://www.aacademica.org/000066/1329.

Marx, Karl. Tesis sobre Feuerbach y otros escritos. México, Grijalbo, 1975. 
Marx, Karl. Manuscritos económicos y filosóficos de 1844. México, Cultura Popular, 1976.

https://www.marxists.org/espanol/m-e/1840s/manuscritos/index.htm

Mora Salas, Minor. "El empleo precario asalariado y globalización: enseñanzas desde Costa Rica. En Trabajos atípicos y precarización del empleo, editado por Pacheco, Edith, Enrique de la Garza y Luis Reygadas, 161-198. México: El Colegio de México, 2011.

Oliveira-Martins, Madalena. Arlie Russell Hochschild: un camino hacia el corazón de la sociología. Madrid: Centro de Investigaciones Sociológicas, 2017.

Pérez Saínz, Juan Pablo. Trabajo global y desigualdades en el mercado laboral. México: Universidad Autónoma del Estado de México Facultad de Ciencias Políticas y Sociales, 2016.

Pérez Sáinz, Juan Pablo. Mercados y bárbaros. La persistencia de las desigualdades de excedente en América Latina. San José: FLACSO, 2014.

Pérez Sáinz, Juan Pablo. Encadenamientos globales y pequeña empresa en Centroamérica. San José: FLACSO, 2002.

Pérez Sáinz, Juan Pablo. From the Finca to the Maquila. Labor and Capitalist Development in Central America. Boulder: Westview Press, 1999.

Pérez Sáinz, Juan Pablo. “¿Es necesario aún el concepto de informalidad? Perfiles Latinoamericanos, Revista de la Facultad Latinoamericana de Ciencias Sociales n. ${ }^{\circ} 13$ (1998): 55-71.

Pérez Sáinz, Juan Pablo. Informalidad urbana en América Latina. Enfoques, problemáticas e interrogantes. Guatemala: Nueva Sociedad, FLACSO, 1991.

Pérez Sáinz, Juan Pablo. Respuestas silenciosas. Proletarización urbana y reproducción de la fuerza de trabajo en América Latina. Caracas: Nueva Sociedad/ FLACSO, 1989.

Piedra Guillén, Nancy. Informe parcial del Proyecto: Pry01-1128-2018 De la maquila textil a la maquila de los servicios: análisis comparativo de las condiciones de empleo, trabajo y vida cotidiana de las y los 
trabajadores de la industria textil y los call centers". Escuela de Sociología, Vicerrectoría de Investigación, UCR, 2018.

Sabido, Olga (2017) "El cuerpo de los amantes. El amor como experiencia sensible en jóvenes universitarios. En: Ana Lidia M. Domínguez Ruíz y Antonio Zirión Pérez, coordinadores. La dimensión sensorial de la cultura. Diez contribuciones al estudio de los sentidos en México. Universidad Autónoma Universitaria Metropolitana, Unidad Iztapalapa. Ediciones Lírio. México.

Sabido, Olga (2012), El cuerpo como recurso de sentido en la construcción del extraño. Una perspectiva sociológica, Madrid, Séquitur.

Sabido, Olga (2015), «Fragmentos amorosos en el pensamiento de Georg Simmel», en Gilberto Díaz Aldana (eds.), Una actitud del espíritu. Interpretaciones en torno a Georg Simmel, Bogotá, Editorial de la Facultad de Ciencias Humanas de la Universidad Nacional de Colombia.

Sabido, Olga (2016), «Cuerpo y sentidos: el análisis sociológico de la percepción», en Debate Feminista, 51(26), pp. 63-80.

Scheff, Thomas J. 1990. Microsociology. Discourse, Emotion, and Social Structure. Chicago: The University of Chicago Press, 1990.

Scheff, Thomas J. What I ove Got to Do With It? Emotions and Relationships in Popular Songs . London: Paradigm Publishers, 2011.

Sennett, Richard. A Corrosão do Caráter. Brasil: Editora Record, 1999.

Simmel, George. Sociología. Estudios sobre las formas de socialización, México, FCE, 2014.

Sojo, Carlos. Igualiticos. La construcción social de la desigualdad en Costa Rica. San José: FLACSO-Costa Rica, 2010.

Trejos París, María Eugenia y Leda Abdallah. Discusión y aplicación de la flexibilidad laboral en Centroamérica. Costa Rica: Espacios Consultores, 2000.

Trejos París, María Eugenia y Minor Mora. Entre la presión y el temor. Condiciones laborales y organizativas en la industria costarricense. Costa Rica: Fundación Friedrich Ebert, 1997. 
Vargas, Gabriel. "Representaciones sociales en torno al trabajo: procesos de construcción identitaria, realización laboral y transitoriedad en las y los trabajadores de call center en Costa Rica". Tesis de Grado de Licenciatura. Universidad de Costa Rica, 2015.

Vannini, Phillip, Simon. Gottschalk y Dennis. Waskul "The senses in self, society and culture", En A sociology of the senses, Nueva York/ Londres, Routledge, 2012.

Weber, Max. La ética protestante y el espíritu del capitalismo, México D.F., Ediciones Coyoacán, 1999.

Zapata, Francisco. Prologo. En Desentrañar el sentido del trabajo. Hacia la comprensión de las configuraciones identitarias laborales. Autor Marcel, Geyser, 7-16 México: El Colegio de México, 2010. 